\title{
Basic vascular research conducted by Japanese anesthesiologists
}

\section{Opening remarks}

\author{
Yuichi Kanmura $\cdot$ Shigeru Saito
}

Received: 29 August 2011/Published online: 20 November 2011

(C) Japanese Society of Anesthesiologists 2011

The JA Symposium, sponsored by the Journal of Anesthesia (JA), traces its origins to the annual meeting of the Japanese Society of Anesthesiologists (JSA) in 2006. Initially, this symposium was held to promote dissemination of information about significant advances in the field of anesthesia and submission to the JA. We appreciate your strong support and contribution during the past 5 years. The continued success of the JA symposium pushed the JA to a record high, with an impact factor of 0.837 in 2009 . We hope that our authors, readers, and reviewers will share this success with us, and that the editorial team will continue their hard work to hit another new high in the future.

Since the first publication, the JA symposium has highlighted outstanding research related to respiratory disorders and neurological pathologies. This year, we focused on leading achievements in cardiovascular research and selected five distinguished presentations. The authors were asked to present current trends in vascular investigations showing their own original data.

To begin the symposium, Saito [1] reviewed pioneering circulation research conducted by Japanese scientists. After the introduction, Kinoshita [2] explained the effects of oxidative stress on vascular function and demonstrated that some anesthetics have a significant effect on this oxidative stress. Iida [3] reported that several drugs administered during anesthesia affect the cerebrospinal microcirculation. He

\section{Y. Kanmura}

Department of Anesthesiology and Critical Care Medicine, Kagoshima University Graduate School of Medicine and Dental Sciences, Kagoshima, Japan

\section{S. Saito $(\bowtie)$}

Department of Anesthesiology, Gunma University Graduate

School of Medicine, 3-39-22 Showa-machi,

Maebashi 371-8511, Japan

e-mail: shigerus@showa.gunma-u.ac.jp stressed the importance of preventing cerebrospinal ischemia during surgery. Tsuneyoshi [4] demonstrated vascular reactivity in human vascular smooth muscle. Because genuine human vascular specimens were used in his studies, the clinical applicability of his results seems high. In the last presentation, Kawano [5] released his current findings regarding electrophysiological analysis of ATP-sensitive potassiumchannel regulation. His results have many implications for vascular pharmacology. Summaries of the presentations mentioned above are published in the following pages.

As the organizers of this symposium, we hope it will lead to the development of cardiovascular research from the standpoint of anesthesiologists. In particular, we hope that the contents of this symposium will inspire potential young investigators currently working in operating theaters or intensive care units. Although the targets of funding and social interest fluctuate over a variety of sub-specialties, for example regeneration medicine and brain science, it is unquestionably true that circulation medicine and vascular biology are still in the main stream of medical science, especially for anesthesiologists and intensivists.

\section{References}

1. Saito S. Outstanding circulation research by Japanese scientists. J Anesth. 2011. doi:10.1007/s00540-011-1282-5.

2. Kinoshita $\mathrm{H}$. Effects of oxidative stress on the vascular function and the role of anesthetics. J Anesth. 2011. doi:10.1007/s00540-011-1283-4.

3. Iida H. Iida M, Takenaka M. Anesthesia and cerebrospinal microcirculation-assessment using cranial and spinal window techniques. J Anesth. 2011. doi:10.1007/s00540-011-1284-3.

4. Tsuneyoshi I. Vascular reactivity in human arteries: from experimental study to clinical application. J Anesth. 2011. doi:10.1007/ s00540-011-1285-2.

5. Kawano T. Functional roles of ATP-sensitive potassium channel as related to anesthesia. J Anesth. 2011. doi:10.1007/s00540-011-1286-1. 